\title{
Development of wellbore compound blockage removal technology to reduce production loss in the ultra-deep and high-sulfur Yuanba gas field
}

\author{
Wei Luo ${ }^{1} \cdot$ Qiang $\mathrm{Wu}^{2}$
}

Received: 3 June 2020 / Accepted: 3 September 2020 / Published online: 15 September 2020

(c) The Author(s) 2020

\begin{abstract}
Wellbore compound blockage occurs in several wells of Yuanba gas field during production, which seriously affects the stable production. The prior treatment with inorganic acid injection does not show a good effect. Therefore, it is urgent to establish an effective blockage removal technology. In this work, the composition analysis of compound blockage samples is firstly carried out. Then, two types of acid solution and barite dissolvent for different types of wellbore blockage are developed. Finally, the corresponding crafts of wellbore blockage removal for different degrees of wellbore blockage are set up. Analysis results show that the inorganic components of blockages are mainly $\mathrm{FeS}_{2}, \mathrm{CaCO}_{3}, \mathrm{BaSO}_{4}$, and $\mathrm{SiO}_{2}$. The organic components of blockages are mainly the decomposition products of macromolecular materials and the asphaltene. There are differences in the components of blockages between different wells in Yuanba gas field. Some wells are the type of organic-based blockage, while others are the type of inorganic-based blockage. The field application shows that the developed wellbore compound blockage removal technology has successfully guided the in situ removal operation of eight wells in Yuanba gas field, ensuring the smooth completion of production task of this gas field. This effective blockage removal technology can be extended to similar ultra-deep and high-sulfur gas field.
\end{abstract}

Keywords Yuanba gas field · Wellbore compound blockage $\cdot$ Composition analysis $\cdot$ Acid solution $\cdot$ Removal technology

\section{Introduction}

Yuanba gas field is a large marine gas field with 100 billion cubic meters reserves in Sichuan basin discovered by Sinopec after Puguang gas field. It is located in the southwest of Bazhong block in the northeast of Sichuan Province. Yuanba gas field is characterized by ultra-deep $(6500 \mathrm{~m}+)$, high temperature $\left(150^{\circ} \mathrm{C}\right)$, high pressure $(70 \mathrm{MPa})$, and high sulfur content (5\%), which is a typical "three highs" gas reservoir (Dou et al. 2012; Aldawsari et al. 2017; Liu et al. 2015). Meanwhile, Yuanba gas field is a low-porosity and low-permeability reservoir with the porosity of $4.53 \%$ and the permeability of $0.34 \mathrm{md}$. Yuanba gas field has built an

Wei Luo

176159172@qq.com

1 Nanchong Vocational and Technical College, Nanchong 637131, China

2 Research Institute for Engineering Technology, Sinopec Southwest Branch Company, Deyang 618000, China annual capacity of 3.4 billion cubic meters since it was officially put into production in December 2014 (Guo 2019; Ma et al. 2014; Guo et al. 2018). However, a series of problems occurs along with the production, the most serious of which is the wellbore compound blockage.

In order to release the reservoir productivity as much as possible, 76 percent of wells in Yuanba gas field are completed with open hole or liner (Su et al. 2014). Meanwhile, the reaction of acid and rock also reduces the cementation strength of rock in the near-wellbore region; therefore, the wellbore support is weak and there is a great risk of spalling of formation cuttings. At the same time, as the production the downhole corrosion products, the temporary blocking agent and fiber, the drilling and completion fluid residue, the decomposition products of gelling agents and corrosion inhibitors at high temperature, the asphaltene, and other materials return together. The organic substances are accompanied by the inorganic matters in the return process, resulting in the wellbore compound blockage in several wells in Yuanba gas field, which seriously affects the stable production. 
The current methods used in the industry to remove the wellbore compound blockages mainly include the thermal treatment and the chemical treatment (Bernardier 1993; Frost et al. 2008; Quintero et al. 2017). The injection of hot oil or hot water is used as the thermal treatment (Zhang et al. 2020; Creek 2012; Ding et al. 2017). The chemical treatment primarily refers to the injection of acid and other chemical solvents (Davudov et al. 2018; Pietrangeli et al. 2014). Therefore, in the early stage the injection of hot water and inorganic acid is used to remove the wellbore compound blockages for most blockage wells of Yuanba gas field. However, the removal effect is not ideal and repeated blockage occurs for many blockage wells. The main reason is that the treatment is not targeted due to the unclear blockage composition. There should be differences in the components of wellbore compound blockages between different blockage wells. Different types of wellbore compound blockage need to take different blockage removal technology (including different acid solutions and removal crafts). Therefore, the composition analysis of compound blockage samples for different gas wells is important and urgent. Once the composition analysis is completed, the targeted acid solution and removal craft can be taken out to obtain ideal effect.

Therefore, in this work, the composition analysis of compound blockage samples is firstly carried out through the indoor experiment. Then, the targeted acid solutions for inorganic-based blockage and organic-based blockage, the sampling tool and the blockage removal crafts for different types and degrees of wellbore blockage are developed to form the wellbore compound blockage removal technology suitable for the ultra-deep and high-sulfur gas field. The application of the developed blockage removal technology increases the daily production of Yuanba gas field by $318 \times 10^{4} \mathrm{~m}^{3}$ and shows very good results.

\section{Current situation of wellbore compound blockage}

\section{Statistics of wellbore compound blockage}

A total of 33 wells have been put into production in Yuanba gas field, including nine wells with openhole completion, sixteen wells with liner completion, and eight wells with perforated completion. Eight of these wells suffer wellbore compound blockages 22 times in the production process. Table 1 presents the statistics of wellbore compound blockages in Yuanba gas field. Six wells with openhole completion, one well with liner completion, and one well with perforated completion are blocked by wellbore composite. Meanwhile, repeated blockages have occurred in all plugged wells with openhole completion. The main reason for repeated blockages is that formation cuttings, asphaltene and other pumped downhole materials continue to return together in these wells of openhole completion without sufficient borehole support and borehole shielding. Therefore, from the perspective of completion manner, openhole completion is more likely to cause wellbore compound blockage. In terms of the degree of blockage, only one well of YB102-1H is completely blocked, while other wells all form wellbore throttling.

\section{Production dynamic characteristics of blockage wells}

The analysis of production dynamic characteristics is helpful to understand the formation process of wellbore compound blockage and judge the degree of blockage. The change of tubing head pressure (THP) is a direct reflection of production dynamic characteristics. Figures 1, 2, and 3 present three representative types of the THP change in the eight blockage wells. As we can observe, the characteristic of the first type (Fig. 1) is that the THP drops rapidly and there is no obvious

Table 1 Statistics of wellbore compound blockages in Yuanba gas field

\begin{tabular}{llllll}
\hline Well & Blocking time & Blocking location & $\begin{array}{l}\text { Whether completely } \\
\text { blocked }\end{array}$ & $\begin{array}{l}\text { Whether repeatedly } \\
\text { blocked }\end{array}$ & Completion manner \\
\hline YB29-1 & During the production & - & No & Yes & Openhole completion \\
YB27-3H & During the production & $6380 \mathrm{~m}$ & No & Yes & Openhole completion \\
YB102-1H & During the production & $6460 \mathrm{~m}$ & Yes & Yes & Openhole completion \\
YB1-1H & After the injection of Annu- & - & No & Yes & Yes \\
YB102-3H & lus protection liquid & During the production & - & No completion & Openhole completion \\
YB103-1H & During the production & - & No & Yes & Openhole completion \\
YB205-1 & During the production & - & No & No & Liner Completion \\
YB204-2 & During the production & - & No & No & Perforation completion \\
\hline
\end{tabular}



(YB205-1)
Fig. 1 Production dynamic characteristic of the first type
Fig. 2 Production dynamic characteristic of the second type (YB103-1H)
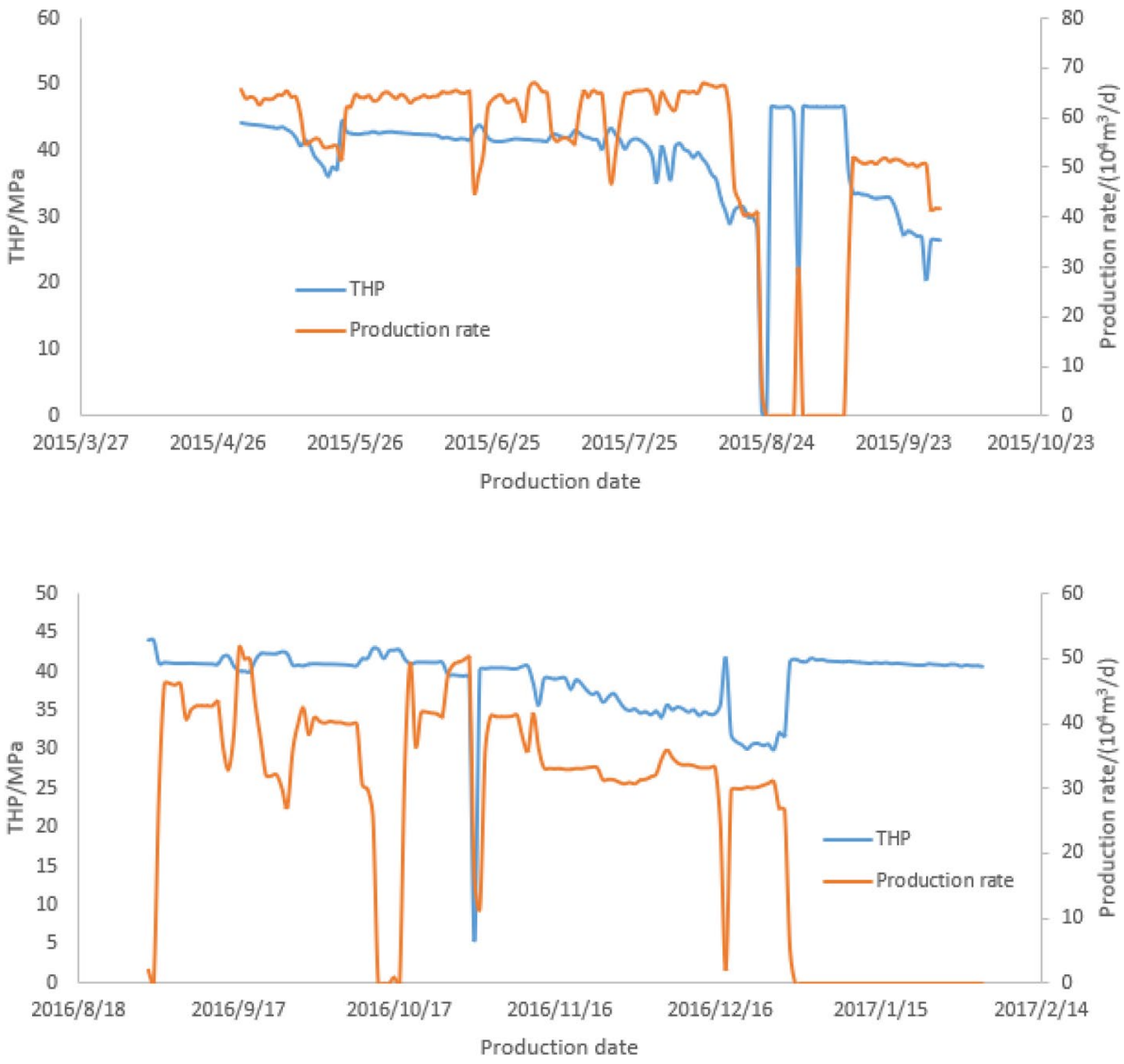

Fig. 3 Production dynamic characteristic of the third type (YB102-1H)

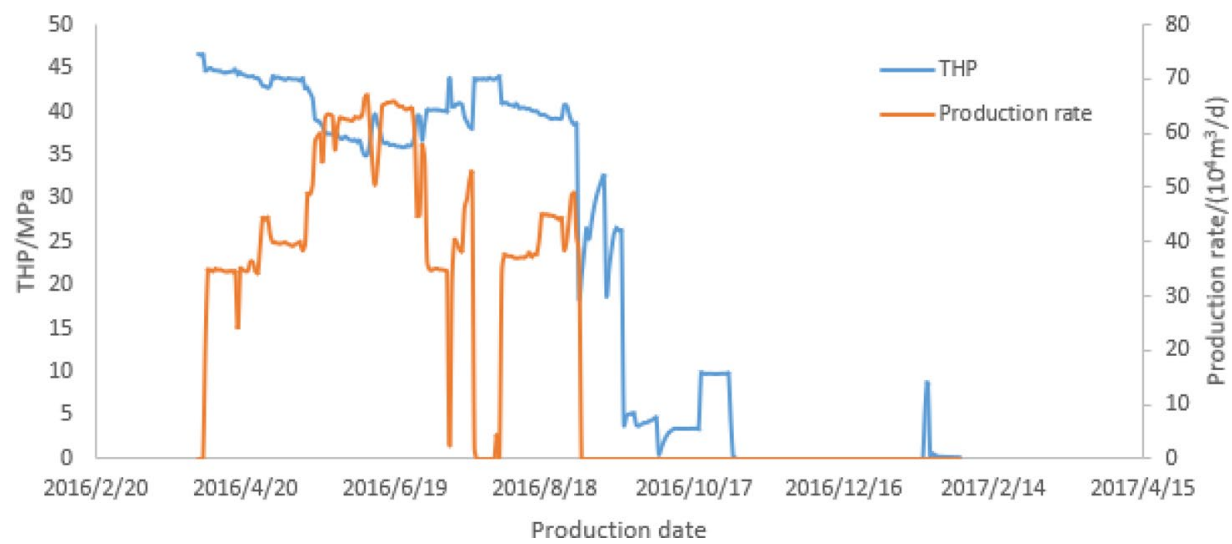

fluctuation during the decline process. Meanwhile, the THP recovers quickly after well shut-in. This characteristic indicates that the wellbore blockage is rapidly formed and the blockage point is only a choke. This type is represented by YB205-1. The second type (Fig. 2) is characterized as follows: The THP drops slowly with slight fluctuations during the decline process. Also, the THP recovers quickly after well shut-in. This characteristic indicates that the wellbore blockage develops gradually and fluctuates slightly during the formation process and the blockage point is also only a choke. This type is represented by YB103-1H. The characteristic of the third type
(Fig. 3) is that the THP drops rapidly and simultaneously it is difficult to restore the THP after well shut-in because the wellbore is completely blocked. This type is represented by YB102-1H. 

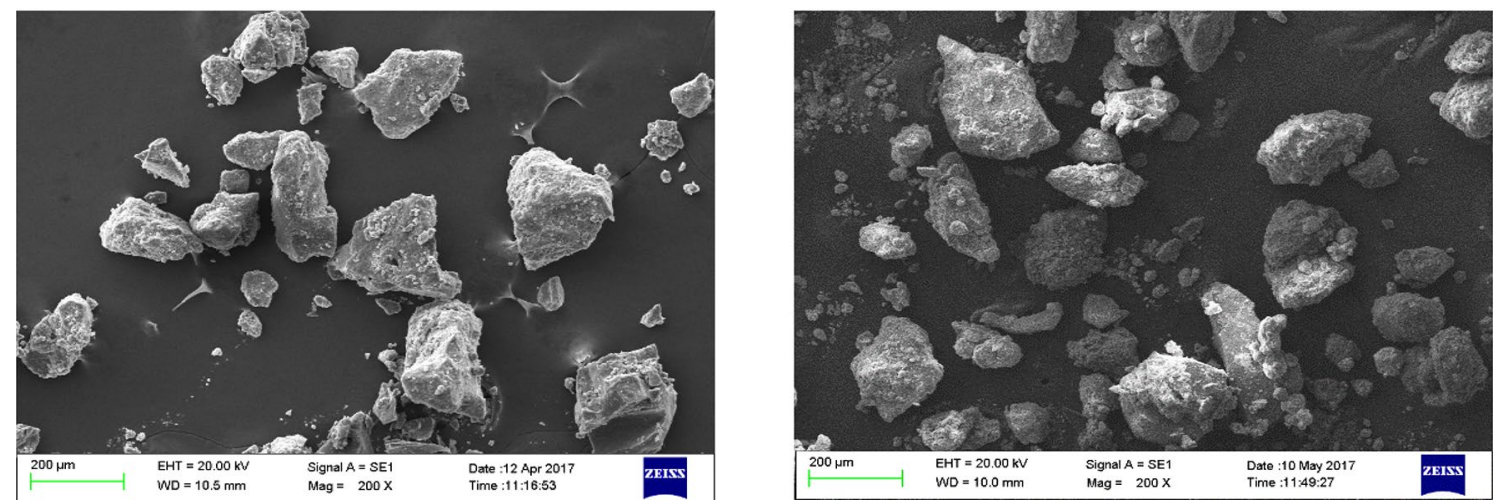

Fig. 4 Morphology of the blockage samples obtained from SEM of YB27-3H and YB102-1H (200×)

Table 2 Results of element analysis of the blockage samples

\begin{tabular}{lllllllllll}
\hline Well & \multicolumn{1}{l}{ Element content } & & & & & & & & \\
\hline YB27-3H & $\mathrm{C}$ & $\mathrm{O}$ & $\mathrm{S}$ & $\mathrm{Fe}$ & $\mathrm{Na}$ & - & - & - & - & - \\
& $32.60 \%$ & $2.97 \%$ & $24.31 \%$ & $23.86 \%$ & $1.13 \%$ & - & - & - & - & - \\
YB102-1H & $\mathrm{C}$ & $\mathrm{O}$ & $\mathrm{S}$ & $\mathrm{Fe}$ & $\mathrm{Al}$ & $\mathrm{Si}$ & $\mathrm{Ca}$ & $\mathrm{Cr}$ & $\mathrm{Ni}$ & $\mathrm{Ba}$ \\
& $63.64 \%$ & $13.7 \%$ & $3.35 \%$ & $5.39 \%$ & $0.33 \%$ & $1.14 \%$ & $3.61 \%$ & $0.49 \%$ & $0.89 \%$ & $3.59 \%$ \\
\hline
\end{tabular}

\section{Composition analysis of compound blockage}

The composition analysis of compound blockage samples acquired from YB27-3H and YB102-1H is carried out, including element analysis, inorganic composition analysis, organic composition analysis, thermogravimetric analysis, and solubility analysis of blockage samples in acid and ethanol. Once the composition of blockage samples is clear, the type of acid solution used for wellbore blockage removal can be selected and determined.

\section{Element analysis}

Scanning electron microscope (SEM) is used to observe the morphology of the blockage samples. Figure 4 shows the morphology diagram of the samples magnified by 200 times. From the figure shown, the sample size distribution of YB27-3H and YB102-1H is basically uniform.

Then, the distribution of element content in the selected microzone of samples is analyzed by X-ray energy spectrometer. The analysis results are presented in Table 2. As we can observe, the main elements of compound blockages of the two wells are $\mathrm{C}, \mathrm{O}, \mathrm{S}$, and $\mathrm{Fe}$, which are primarily from the reservoir fluids and formation cuttings. Meanwhile, the metal elements including $\mathrm{Cr}$ and $\mathrm{Ni}$ are detected in YB102-1H, which may be related to the milling of tubing in the process of blockage removal of this well.
Table 3 Results of energy spectrum analysis of the blockage samples

\begin{tabular}{llll}
\hline Well & \multicolumn{4}{l}{ Inorganic composition } \\
\hline YB27-3H & $\mathrm{FeS}_{2}$ & $\mathrm{BaSO}_{4}$ & - \\
& $86.53 \%$ & $13.47 \%$ & - \\
YB102-1H & $\mathrm{CaCO}_{3}$ & $\mathrm{BaSO}_{4}$ & $\mathrm{SiO}_{2}$ \\
& $76.93 \%$ & $17.55 \%$ & $5.52 \%$ \\
\hline
\end{tabular}

\section{Inorganic composition analysis}

$\mathrm{X}$-ray diffractometer is used to analyze the inorganic composition of the blockage samples. From the energy spectrum analysis results (Table 3) shown, the inorganic compositions of $\mathrm{YB} 27-3 \mathrm{H}$ are mainly $\mathrm{FeS}_{2}$ and $\mathrm{BaSO}_{4}$, while those of $\mathrm{YB} 102-1 \mathrm{H}$ are mainly $\mathrm{CaCO}_{3}, \mathrm{BaSO}_{4}$, and $\mathrm{SiO}_{2}$. There is a difference in the inorganic compositions of blockage samples of the two wells. The cause of the difference is that the two wells are in different blocks of Yuanba gas field and the inorganic compositions may come from different rock types. $\mathrm{FeS}_{2}$ may come from rock mineral components or be the corrosion reaction product of downhole strings and $\mathrm{H}_{2} \mathrm{~S}$. $\mathrm{CaCO}_{3}$ may come from rock mineral components or the temporary blocking agent added during acidizing treatment. $\mathrm{BaSO}_{4}$ may be from the weighting material added to the drilling fluid. $\mathrm{SiO}_{2}$ may come from rock mineral components. 


\section{Organic composition analysis}

Infrared spectrometer is used to analyze the organic composition of the blockage samples. From the infrared spectrogram (Fig. 5) shown, for YB27-3H, $2901 \mathrm{~cm}^{-1}$ is the characteristic peak of $-\mathrm{CH}_{2}$ which is preliminarily identified as the heavy hydrocarbon component possibly derived from the decomposition products of organic substances such as SMC, SMP-2, SPNH, DR-8, and RH-220 in the drilling/completion fluid and temporary blocking fiber at high temperature. (The additives in drilling/completion fluid mainly include: $3 \% \mathrm{NV}-1+0.5 \% \mathrm{SMC}+3 \% \mathrm{SMP}-2+3 \% \mathrm{SPNH}+3 \% \mathrm{DR}-$ $8+5 \%$ RH $-220+0.5 \mathrm{NaOH}+1.5 \%$ drag reducer $+8 \%$ weighting material. And the additives in acidizing fluid mainly include: gelling agent, corrosion inhibitor, and temporary blocking fiber.) In the meantime, the morphology of the blockage sample of YB27-3H heated to more than $100{ }^{\circ} \mathrm{C}$ is similar to that of asphalt heated to more than $100^{\circ} \mathrm{C}$. This indicates that the blockage sample of YB27-3H also contains a large amount of asphaltene which is from the reservoir. The conclusion can be further confirmed by the core sample analysis result which shows the core slices of YB27-3H containing $20 \%$ asphaltene. With production, asphaltene in the reservoir gradually returns and adheres to the blockage point.
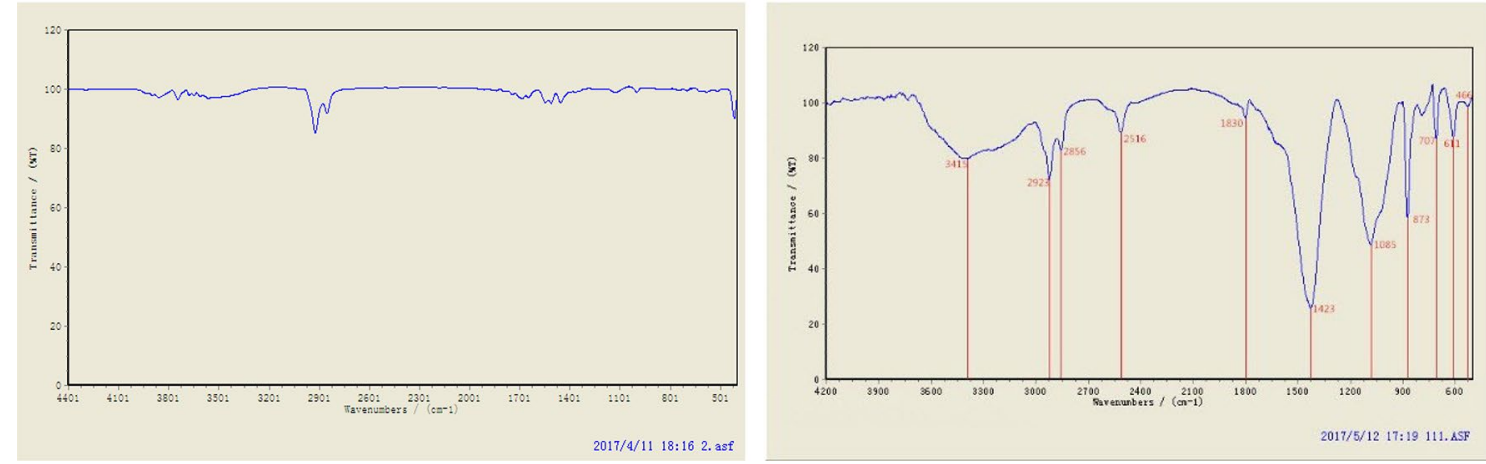

Fig. 5 Results of infrared spectrum analysis of the blockage samples (YB27-3H and YB102-1H)
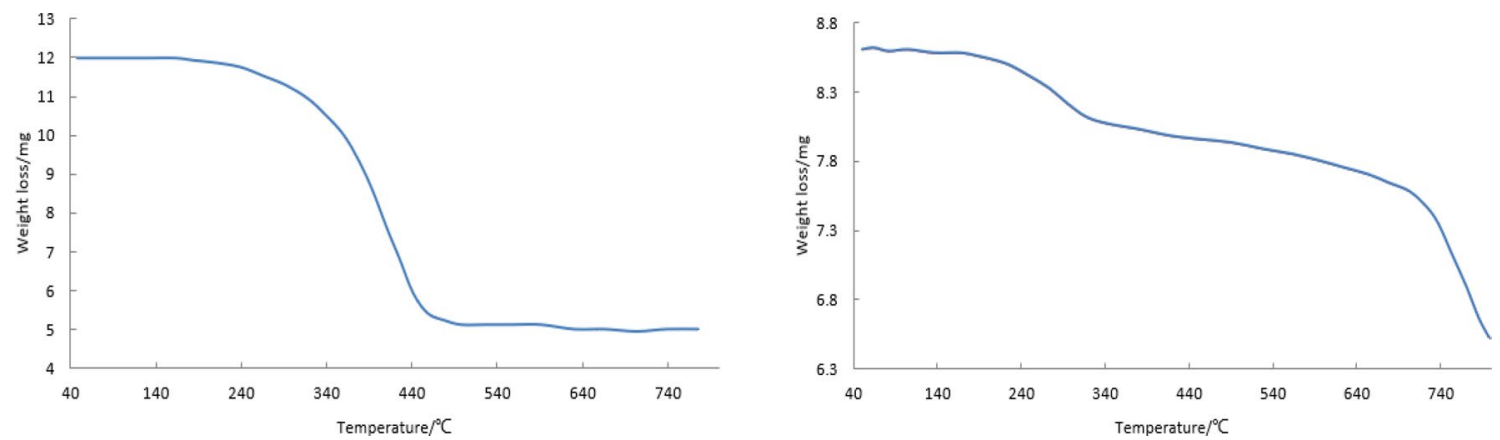

Fig. 6 Relation curve between the temperature and the weight loss of samples of YB27-3H and YB102-1H 
The main reasons for the difference of the proportion of organic substance in the blockage samples are the two wells are in different blocks of Yuanba gas field and the randomness of the return. The reservoirs in different blocks have different asphalt contents. (The asphalt content in the block of YB27-3H is $20 \%$, while the asphalt content in the block of $\mathrm{YB} 102-1 \mathrm{H}$ is $0 \%$.)

\section{Solubility analysis of blockage samples in acid and ethanol}

The blockage samples are placed in $10 \%$ hydrochloric acid solution and organic solvent (ethanol) to react for one hour. The reaction results are presented in Figs. 7 and 8. From the figures shown, for $\mathrm{YB} 27-3 \mathrm{H}$, as soon as the blockage sample is added to the ethanol, it is dissolved quickly, and the color of the solution changes from colorless to light yellow. However, the blockage sample reacts slowly with the hydrochloric acid solution, and there is still a large amount of blockage residue on the solution surface after one hour. For YB102-1H, the blockage sample reacts quickly after contacting with the hydrochloric acid solution. Meanwhile, the reaction releases a lot of gas. However, the blockage sample hardly reacts with the ethanol.

After the reaction, the remaining samples are dried and weighted to calculate the dissolution rate in the two solutions. The calculation results are shown in Table 4. As we can observe, for YB27-3H, the dissolution rate of the blockage sample in $10 \%$ hydrochloric acid solution is only $14.3 \%$, while that in ethanol is $50.87 \%$, indicating that the content
Fig. 7 Reaction results of the blockage sample of YB27-3H in $10 \%$ hydrochloric acid solution and ethanol
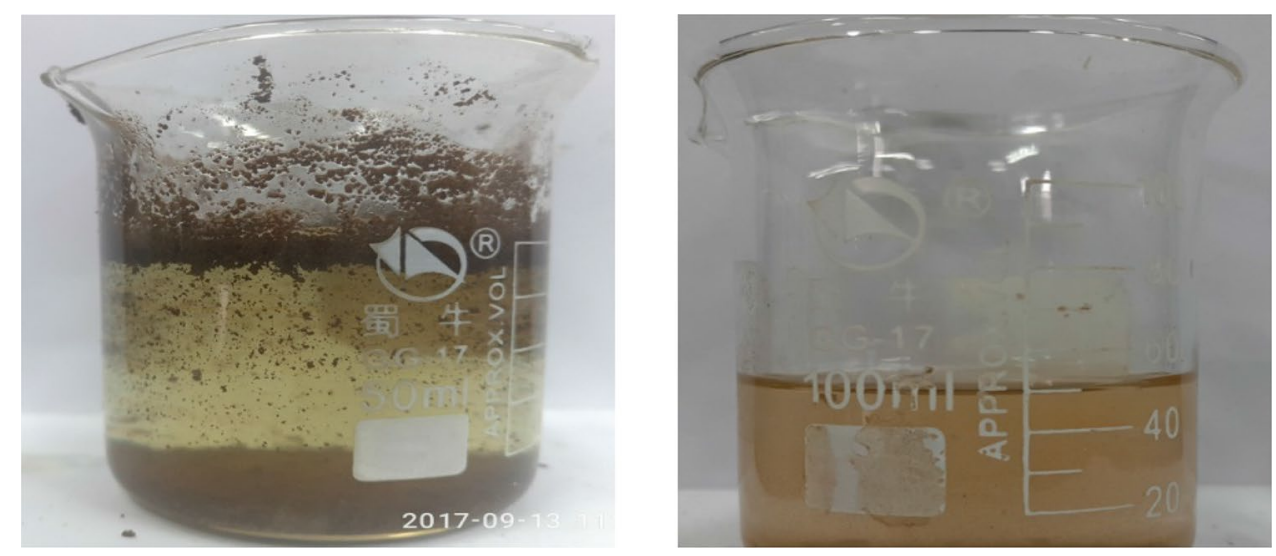

Fig. 8 Reaction results of the blockage sample of YB102-1H in $10 \%$ hydrochloric acid solution and ethanol

Table 4 Dissolution rate of the blockage samples in 10\% hydrochloric acid solution and ethanol
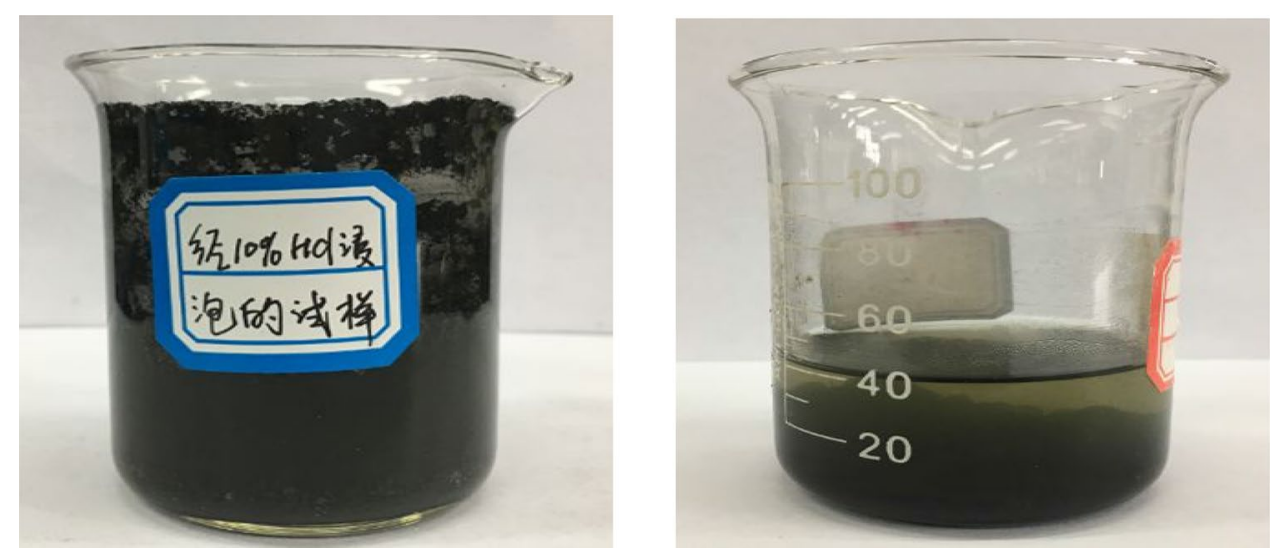

\begin{tabular}{llllll}
\hline Well & Solution type & $\begin{array}{l}\text { Weight } \\
\text { before } \\
\text { reaction/g }\end{array}$ & $\begin{array}{l}\text { Weight } \\
\text { after } \\
\text { reaction/g }\end{array}$ & Lost weight/g & Dissolution/\% \\
\hline YB27-3H & 10\% hydrochloric acid solution & 0.5731 & 0.4912 & 0.0819 & 14.30 \\
& Ethanol & 0.1545 & 0.0759 & 0.0786 & 50.87 \\
YB102-1H & 10\% hydrochloric acid solution & 20.0352 & 12.6997 & 7.3355 & 33.14 \\
& Ethanol & 20.0500 & 18.8730 & 1.1770 & 5.87 \\
\hline
\end{tabular}


of organic substances in the sample is relatively high. For the organic-based blockage, it is easy to remove with organic solvent. For YB102-1H, the dissolution rate of the blockage sample in $10 \%$ hydrochloric acid solution is $33.14 \%$, while that in ethanol is only $5.87 \%$, indicating that the proportion of inorganic substances in the sample is relatively high. For the inorganic-based blockage, the inorganic acid is relatively effective to dissolve it.

\section{Wellbore compound blockage removal technology}

\section{Acid solution}

According to the composition analysis results, it is clear that there are differences in the components of wellbore compound blockages between different gas wells. Therefore, two kinds of acid solution formulas that are, respectively, suitable for inorganic-based blockage and organic-based blockage are developed, as follows:

1. Inorganic acid solution formula (suitable for inorganicbased blockage): $20 \% \mathrm{HCl}+5.5 \%$ high temperature corrosion inhibitor $+1.0 \%$ iron ion stabilizer $+1.0 \%$ cleanup additive.

2. Organic acid solution formula (suitable for organicbased blockage): $5 \% \mathrm{HCl}+10 \%$ primary emulsion $+0.4 \%$ auxiliary emulsion $+43 \%$ specific organic solvent $+0.1 \%$ organic salt $+10 \%$ mutual solvent $+4 \%$ high temperature corrosion inhibitor $+0.8 \%$ iron ion stabilizer $+0.1 \%$ defoaming agent + water.

In order to evaluate the performance of the newly developed organic acid solution, the dissolution experiments at normal temperature and at high temperature are carried out, respectively.

\section{Normal temperature}

The experiment steps at normal temperature are as follows: (1) Firstly, the blockage samples of YB27-3H (organicbased) are placed in the inorganic acid solution and the organic acid solution, respectively, and the experiment temperature is $30^{\circ} \mathrm{C}$, (2) then stirring the solution at the speed of 200 RPM for ten minutes and observing. The experiment results are shown in Fig. 9. As we can observe from the first picture, the organic-based blockage samples hardly react with the inorganic acid solution; therefore, the color of the solution and the volume of the blockage samples hardly change. However, from the second picture shown, the blockage samples react quickly in the developed organic acid solution; meanwhile, the reaction releases a lot of gas and the blockage samples are almost completely dissolved. The experiment results show that the developed organic acid solution is very effective for dissolving the organic-based blockage samples at normal temperature.

\section{High temperature}

There are two purposes for conducting the high-temperature experiment. One is to evaluate the dissolution performance of organic acid solution at high temperature, and the other is to observe if any new substance is produced after the dissolution reaction. The experiment steps are as follows: (1) Firstly, the blockage samples of YB27-3H are placed in the organic acid solution, and then stirring the solution at the speed of 200 RPM for ten minutes; (2) secondly, the mixture solution is poured into the aging pot, pressurized to $1 \mathrm{MPa}$, and placed in a $160{ }^{\circ} \mathrm{C}$ constant temperature oven to fully react for $72 \mathrm{~h}$. After the experiment, the mixture solution is taken out from the aging pot for observation. The experiment results show that: the organic-based blockage samples are almost completely dissolved in the developed organic acid solution at high temperature and no new substance is formed after the high-temperature reaction. Therefore, the developed
Fig. 9 Dissolution experiment results of the organic-based blockage samples in two types of acid solution
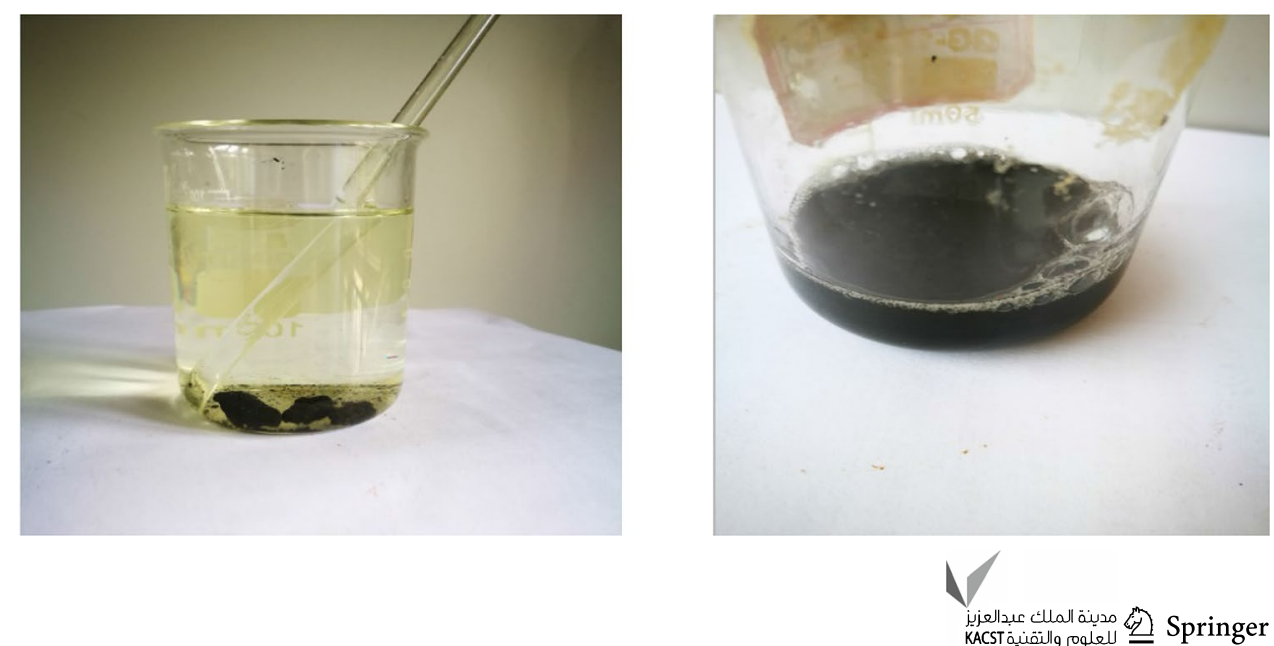
organic acid solution is also very effective for dissolving the organic-based blockage samples at high temperature.

\section{Barite dissolvent}

Barite that enters the formation during the drilling process returns gradually along with the production, resulting in a large amount of barite in the compound blockage, which has been confirmed by the composition analysis. Barite is an inert substance, and its dissolution rate in the inorganic acid solution is extremely low $(<2 \%)$. Therefore, a barite dissolvent mainly composed of several complexing agents, penetrating agent, and wetting agent is developed. The new developed dissolvent dissolves the barite by complexation. Then, the dissolution performance of the barite dissolvent is evaluated by experiments. The experiment results are presented in Table 5. From the table shown, the dissolution rate of barite after reaction in the new developed dissolvent at $110{ }^{\circ} \mathrm{C}$ for $48 \mathrm{~h}$ reaches $52 \%$, which is significantly higher than that in inorganic acid solution.

\section{Sampling tool of wellbore blockage}

According to the investigation, the traditional fishing tool is mainly used to collect the inherent impurities in the bottom hole that cannot satisfy the integration of scraping and fishing the wall attachment. Therefore, an integrated sampling tool for scraping, circularly flushing, and collecting wellbore blockages is developed. The components of the sampling tool include: inclined downward nozzle, inclined upward nozzle, scraper, storage cavity, non-return valve, and filter screen. The tool structure is shown in Fig. 10.

Tool working principle: dragging the tool up and down to scrape the tubing wall. At the same time, the wellbore establishes direct flushing. The fluid is ejected from the inclined downward nozzle to flush the tubing wall, and the fluid moves downward into the non-return valve and passes through the filter screen to leave the wellbore blockages in the storage cavity. Finally, the fluid returns the annulus through the inclined upward nozzle. The tool parameters are as follows: tool length $2 \mathrm{~m}$, maximum outer diameter $55 \mathrm{~mm}$, tool wall thickness $4 \mathrm{~mm}$, minimum inner diameter 28-30 mm, nozzle diameter $10 \mathrm{~mm}$, and nozzle opening angle $15^{\circ}$.

\section{Crafts of wellbore blockage removal}

\section{Throttled wellbore}

Inorganic-based blockage The inorganic acid solution and the barite dissolvent are directly pumped into the wellbore through two-stage injection. The total injected liquid volume is three times of the wellbore volume, and the operational displacement is controlled within $0.4 \mathrm{~m}^{3} / \mathrm{min}$ in order to extend the reaction time between the injected solutions and the compound blockage. Then, a tubing volume of water is used to squeeze the injected solutions into the formation.

Table 5 Dissolution experiment results of barite

\begin{tabular}{|c|c|c|c|c|c|c|}
\hline Fluid & Temperature $/{ }^{\circ} \mathrm{C}$ & $\begin{array}{l}\text { Weight before } \\
\text { reaction/g }\end{array}$ & $\begin{array}{l}\text { Weight of filter } \\
\text { paper/g }\end{array}$ & $\begin{array}{l}\text { Total weight after } \\
\text { reaction/g }\end{array}$ & Dissolution/\% & $\begin{array}{l}\text { Average } \\
\text { dissolu- } \\
\text { tion/\% }\end{array}$ \\
\hline \multirow[t]{4}{*}{ Barite dissolvent } & 45 & 2.0003 & 1.3832 & 2.6165 & 38.34 & 38.21 \\
\hline & & 2.0002 & 1.3628 & 2.6013 & 38.08 & \\
\hline & 110 & 2.0004 & 1.3866 & 2.3409 & 52.29 & 52.54 \\
\hline & & 2.0003 & 1.3986 & 2.3431 & 52.78 & \\
\hline
\end{tabular}

Fig. 10 Structure diagram of the sampling tool

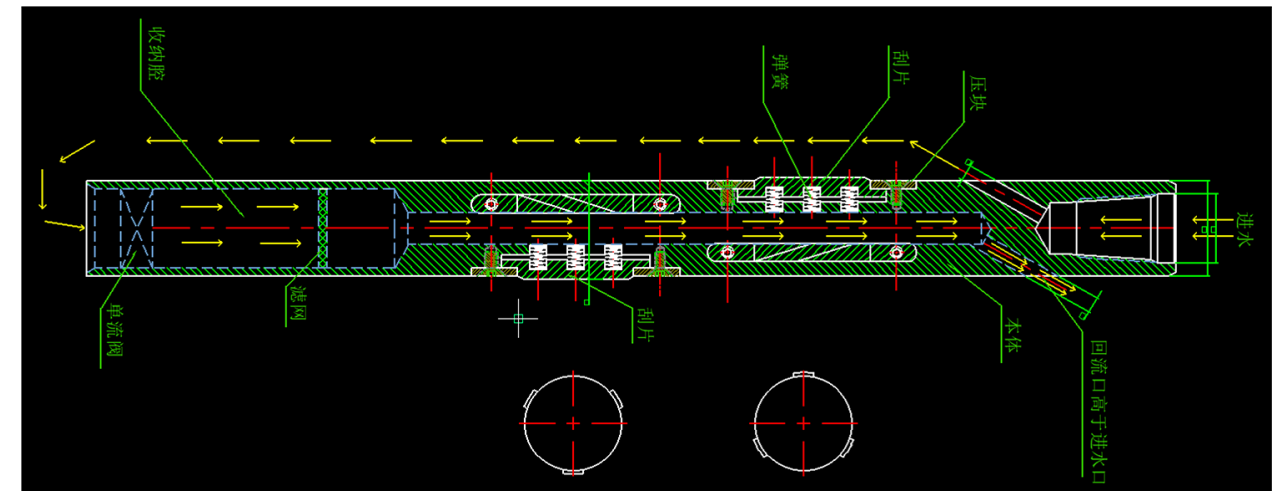


Organic-based blockage (1) Firstly, the coiled tubing is used to look for the surface of wellbore blockage. The running speed of coiled tubing is controlled within $10 \mathrm{~m} / \mathrm{min}$ to avoid sudden contact with the blockage point, which will lead to excessive downward pressure and flexural deformation of coiled tubing. (2) After the surface of wellbore blockage is explored, the coiled tubing is used to pump the washing fluid to flush the blockage point continuously, and the operational displacement is controlled at $0.3 \mathrm{~m}^{3} / \mathrm{min}$. (3) If pumping the washing fluid is not effective, the organic acid solution is used to flush the blockage point. The operational displacement is controlled at $0.20 .3 \mathrm{~m}^{3} / \mathrm{min}$. (4) If the wellbore blockage still cannot be removed, the coiled tubing is raised $500 \mathrm{~m}$ above the blockage point and the organic acid solution is pumped. Then, the washing fluid is used to replace the organic acid solution out of the tubing. The coiled tubing is raised $1000 \mathrm{~m}$ again, and the wellbore blockage is made to soak in the organic acid solution for $2 \mathrm{~h}$. (5) Finally, the coiled tubing is pulled out of the wellbore and the inorganic acid solution is pumped from the wellhead. Then, a tubing volume of water is used to squeeze the injected solutions into the formation.

The type of compound blockage is not determined The sampling tool carried by coiled tubing is used to scrape, flush, and collect wellbore blockages. The composition analysis is performed after collecting the blockage samples. Once the type of wellbore blockage is determined, targeted craft will be taken. Performance requirements of the flushing fluid include high temperature resistance, low friction resistance, and strong sand carrying capacity. Meanwhile, it is required that the viscosity should be above $80 \mathrm{~s}$ and the $\mathrm{pH}$ value should be above 10 . The friction reducing water with the density of $1.0 \mathrm{~g} / \mathrm{cm}^{3}$ is adopted as the flushing fluid. Considering that the production gas contains $\mathrm{H}_{2} \mathrm{~S}, 2 \%$ organic sulfur removal agent is added into the flushing fluid.

\section{Completely blocked wellbore}

In the case of completely blocked wellbore, it is more likely that metal hard objects and returned formation impurities are cemented together to form wellbore blockage. For this type of wellbore blockage, the following removal method is adopted: (1) firstly using the coiled tubing to look for the surface of wellbore blockage. (2) Flushing the blockage point: gradually increase the displacement, and the maximum displacement is limited to the pump pressure not exceeding $50 \mathrm{MPa}$. (3) Drilling and milling the blockage point: The coiled tubing with screw motor and milling guide is adopted. (4) Squeezing, acid bathe, acid fracturing: The type of acid solution is chosen according to the composition analysis. If the wellbore blockage is removed, then a tubing volume of water is used to squeeze the acid solution into formation. Otherwise, the coiled tubing is used to replace the acid solution out of the wellbore. (5) Lead pattern print: The coiled tubing with lead pattern is used to print the blockage point. (6) Logging, positioning, and perforation with coiled tubing: If the blockage point is below the packer after logging and positioning, the perforation is carried out with coiled tubing in order to communicate the annulus and the formation.

\section{Field application}

Since 2015, the wellbore compound blockage removal technology has been successfully applied to eight blockage wells of Yuanba gas field, ensuring the smooth completion of the production task. The well of YB102-1H is the type of completely blocked wellbore. For this well, a series of measures such as flushing, drilling and milling the blockage point, squeezing, acid bathe, acid fracturing, lead pattern print, logging, positioning and perforation with coiled tubing are adopted to successfully communicate the formation. However, the early removal effect of YB27-3H is not ideal by using the craft of inorganic-based blockage removal. Through the composition analysis of the blockage samples, it is found that the wellbore blockage type of YB27-3H is organic-based blockage. Then, the method of organic-based blockage removal is adopted to achieve good results. In the following part, the blockage removal process and effect of YB27-3H will be introduced comprehensively.

\section{Early basic situation of YB27-3H}

YB27-3H conducted the wellbore blockage removal by using inorganic acid solution in November 2016, February 2017, April 2017, and August 2017, respectively. The tubing head pressure (THP) is recovered after the removal of wellbore blockage, but the validity period was only 60 days, 51 days, 73 days, and 28 days, respectively. The well again experienced a significant drop in THP on September 15, 2017. According to the variation characteristic of THP, it was concluded that there was a repeated blockage point in the wellbore. This blockage point was not completely dissolved each time by using inorganic acid solution, and it was prone to accumulate formation returns after reproduction.

\section{Wellbore blockage removal process}

According to the results of composition analysis of the blockage samples, YB27-3H adopted the craft of organic-based blockage removal on November 9, 2017. The implementation process was as follows: (1) Firstly connecting the downhole tools, the string structure from top to bottom was: $\Phi 44.45 \mathrm{~mm}$ coiled 
Fig. 11 Production dynamic characteristic of YB27-3H

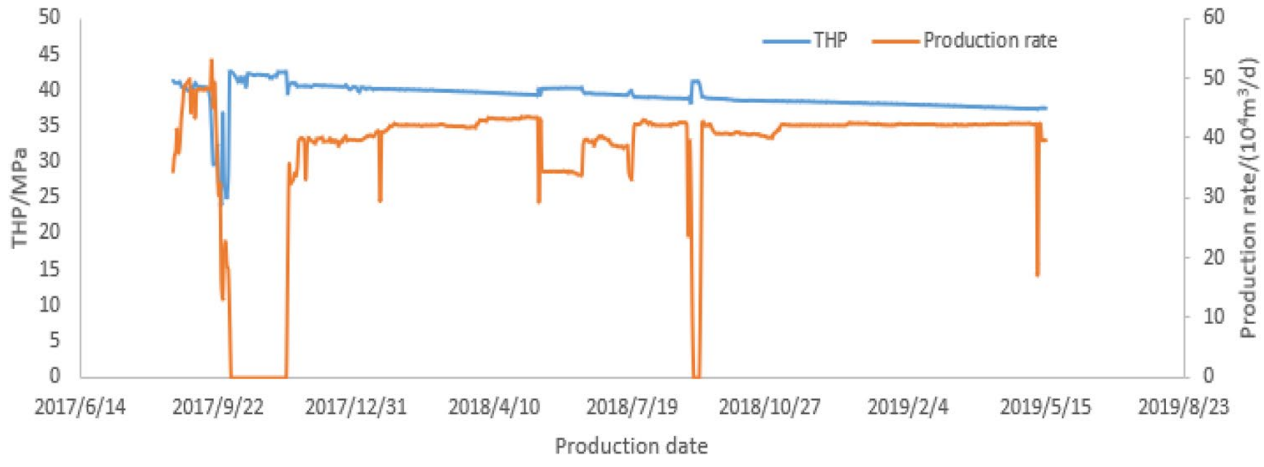

tubing $+\Phi 44.45 \mathrm{~mm} \times 0.05 \mathrm{~m}$ joint $+\Phi 44.45 \mathrm{~mm} \times 0.46 \mathrm{~m}$ non-return valve $+\Phi 44.45 \mathrm{~mm} \times 0.49 \mathrm{~m}$ hydraulic release sub $+\Phi 44.5 \mathrm{~mm} \times 0.1 \mathrm{~m}$ ball nozzle. (2) Squeezing the water to kill well from the tubing. (3) The string was stuck at the depth of $6380 \mathrm{~m}$ with a 10 ton reduction in suspending weight, then pumping the washing fluid to flush the blockage point with a displacement of $0.3 \mathrm{~m}^{3} / \mathrm{min}$ and pump pressure of $24 \mathrm{MPa}$ for $40 \mathrm{~min}$, but there was no forward footage. (4) Afterward, pumping the organic acid solution to flush the blockage point with a displacement of $0.20 .3 \mathrm{~m}^{3} / \mathrm{min}$ and pump pressure of $2542 \mathrm{MPa}$. The string suspending weight returned to normal when the cumulative acid injection amount reached $10 \mathrm{~m}^{3}$, indicating that the wellbore blockage had been successfully removed. (5) Pumping the washing fluid to further flush the wellbore to the depth of $6438 \mathrm{~m}$. (The depth of casing shoe is $6408 \mathrm{~m}$.) (6) Lifting the string and flushing the well section $63806390 \mathrm{~m}$ back and forth. (7) Pulling the string out of the wellbore and removing the wellhead equipment of coiled tubing. (8) Pumping $20 \mathrm{~m}^{3}$ of the inorganic acid solution from the wellhead. Then, a tubing volume of water was used to squeeze the inorganic acid solution into the formation.

\section{Wellbore blockage removal effect}

YB27-3H resumed the normal production on November 13, 2017, after the operation of wellbore blockage removal. The production dynamic characteristic of this well is presented in Fig. 11. As we can observe, after the wellbore blockage removal the THP reached $40.81 \mathrm{MPa}$ and the gas production rate recovered to $43 \times 10^{4} \mathrm{~m}^{3} / \mathrm{d}$; meanwhile, the repeated blockage has not occurred, indicating that the effect of new removal operation is very good.

\section{Conclusions}

1. From the perspective of completion manner, openhole completion without sufficient borehole support and borehole shielding is more likely to cause wellbore compound blockage and repeated blockage.
2. According to the composition analysis, it is found that the inorganic components of wellbore compound blockages are mainly $\mathrm{FeS}_{2}, \mathrm{CaCO}_{3}, \mathrm{BaSO}_{4}$, and $\mathrm{SiO}_{2}$ for Yuanba gas field, which could be from the rock mineral components, the temporary blocking agent, and the weighting material. The organic components of wellbore compound blockages are mainly the decomposition products of macromolecular materials in the drilling fluid and the acidizing fluid at high temperature and the asphaltene from the formation.

3. According to the thermogravimetric analysis and solubility analysis of blockage samples in acid and ethanol, it is found that there are differences in the components of wellbore compound blockages between different wells in Yuanba gas field. Some wells are the type of organicbased blockage, while others are the type of inorganicbased blockage.

4. Two types of acid solution (inorganic acid solution and organic acid solution) and the barite dissolvent are developed for different types of wellbore compound blockages. Different crafts of wellbore blockage removal are developed for different wellbore blockage degrees.

5. The wellbore compound blockage removal technology has been successfully applied to eight blockage wells of Yuanba gas field, increasing the daily production by $318 \times 10^{4} \mathrm{~m}^{3}$. This effective technology can be extended to similar ultra-deep and high-sulfur gas field.

Acknowledgements The authors are grateful for financial support by Sichuan Science and Technology Program (No. 2020JDRC0145), Nanchong Science and Technology Program (No. 19YFZJ0026), and the Doctoral Research Initiation Project of Nanchong Vocational and Technical College (NZYBZ2001).

Open Access This article is licensed under a Creative Commons Attribution 4.0 International License, which permits use, sharing, adaptation, distribution and reproduction in any medium or format, as long as you give appropriate credit to the original author(s) and the source, provide a link to the Creative Commons licence, and indicate if changes were made. The images or other third party material in this article are included in the article's Creative Commons licence, unless indicated otherwise in a credit line to the material. If material is not included in 
the article's Creative Commons licence and your intended use is not permitted by statutory regulation or exceeds the permitted use, you will need to obtain permission directly from the copyright holder. To view a copy of this licence, visit http://creativecommons.org/licenses/by/4.0/.

\section{References}

Aldawsari MA, Al-Sagr AM, Al-Driweesh SM, Al-Shammari NS, Altammar AH, Atayev N, Melo A (2017) HT fracturing fluid in stimulating saudi HTHP gas wells: lab results and field cases[C]// SPE185340. SPE Oil and Gas India Conference and Exhibition, Mumbai, India

Bernardier MG (1993) Advanced asphaltene and paraffin control technology [C]//SPE25192. SPE International Symposium on Oilfield Chemistry, New Orleans, Louisiana, USA

Creek JL (2012) Efficient hydrate plug prevention[J]. Energy Fuels 26:4112-4116

Davudov D, Moghanloo RG, Akita E, Karami H (2018) A diagnostic approach to predict asphaltene deposition in reservoir and wellbore[C]//SPE190149. SPE Western Regional Meeting, Garden Grove, California, USA

Ding L, Shi BH, Wang JQ et al (2017) Hydrate deposition on cold pipe walls in water-in-oil (w/o) emulsion systems. Energy Fuels 31(9):8865-8876

Dou LB, Li GS, Shen ZH, Song XZ, Du T, Chi HP (2012) Study on the well control safety during formation high-sulfur gas invasion[C]// SPE156322. SPE Asia Pacific Drilling Technology Conference and Exhibition, Tianjin, China

Frost KA, Daussin RD, Van Domelen MS (2008) New, highly effective asphaltene removal system with favorable HSE characteristics $[C] / / S P E 112420$. SPE international symposium and exhibition on formation damage control, Lafayette, Louisiana, USA

Guo TL (2019) Gas accumulation conditions and key exploration and development technologies in Yuanba gas field. Acta Petrolei Sinica 40(6):748-760
Guo XS, Hu DF, Li YP, Duan JB, Ji CH, Duan H (2018) Discovery and theoretical and technical innovations of Yuanba gas field in Sichuan Basin. SW China Pet Explor Dev 45(1):14-26

Liu XH, Zhou CM, Liu HL (2015) Diagnosis and analysis of well abnormal flowing data in dina HPHT gas field, west China [C]// SPE177522. Abu Dhabi International Petroleum Exhibition and Conference, Abu Dhabi, UAE

Ma YS, Cai XY, Zhao PR (2014) Characteristics and formation mechanisms of reef-shoal carbonate reservoirs of Changxing-Feixianguan formations. Yuanba Gas Field Acta Pet Sin 35(6):1001-1010

Pietrangeli G, Quintero L, Jones TA, Benaissa S, Menezes CA, Aubry E, Poitrenaud H, Furgier JN (2014) Overcoming wellbore cleanup challenges in deepwater wells in west Africa[C]//SPE168215. SPE International Symposium and Exhibition on Formation Damage Control, Lafayette, Louisiana, USA

Quintero L, Ponnapati R, Felipe MJ (2017) Cleanup of organic and inorganic wellbore deposits using microemulsion formulations: laboratory development and field applications [C]//OTC27653. Offshore Technology Conference, Houston, Texas, USA

Su B, Long G, Xu XQ, Wu Q, Ding D, Wang Y (2014) Safe completion and production technologies of a gas well with ultra depth, high temperature, high pressure and high $\mathrm{H}_{2} \mathrm{~S}$ content: a case from the Yuanba gas field in the Sichuan Basin. Nat Gas Ind 34(7):60-64

Zhang JB, Wang ZY, Tong SK, Gong ZG, Ma N, Sun BJ (2020) Hydrate plugging prevention in deep water gas wells[C]// URTEC-2020-3938. SPE/AAPG/SEG Unconventional Resources Technology Conference, Virtual

Publisher's Note Springer Nature remains neutral with regard to jurisdictional claims in published maps and institutional affiliations. 